\title{
The Implementation of Two-tier Multiple Choice (TTMC) to Analyse Students' Conceptual Understanding Profile on Heat and Temperature
}

\author{
Sukarmin $^{1}$, Suparmi ${ }^{1}$, and Dewi Ratnasari ${ }^{1}$ \\ ${ }^{1}$ Science Education Department of Graduate Program Sebelas Maret University, Surakarta, \\ Indonesia \\ Corresponding e-mail: sukarmin67@staff.uns.ac.id,
}

\begin{abstract}
Conceptual understanding and physics learning process are related to each other. Conceptual understanding makes students able to transform knowledge into multiple representations and application in daily life. The aim of this research is to analyse students' conceptual understanding of heat and temperature by applying instrument Two-tier Multiple Choice (TTMC). This research is a descriptive research with subjects of the research are students of 10th grade in Surakarta in the academic year of 2016/2017 that represents the school with a high, medium and low category. Before instrument TTMC tested to sample, instrument validated by an expert. The instrument TTMC has good content validity between $0.89-1$, the reliability of the first tier is 0.82 , the second tier is 0.70 , difficulty index is a medium category, and distractor index has good function. Based on the data and analysis, most of students in high, medium and low categorized school have low concept understanding in temperature and expansion, in other concepts (heat, Black principle and heat transfer) they have adequate understanding. From this research, teachers know the students' concept understanding, so teachers can choose the suitable learning method in physics learning activities and teachers can develop and apply two-tier multiple choice as alternative instrument to measure students' conceptual understanding.
\end{abstract}

Keywords: concept understanding; heat and temperature; two-tier multiple choice

\section{INTRODUCTION}

One of education aims is to facilitate students to have the conceptual understanding that is expressed verbally and numerically, positivistic thinking design, group life design and spiritual contemplation design [1]. Students' conceptual understanding has become a focus on Physics Education Research (PER) for years. There are many previous types of research that have reported students' learning difficulty [2]. PER has shown that many students who are usually good at solving quantitative problem still experience conceptual difficulty.

Conceptual understanding can be defined variously. Conceptual understanding is commonly defined as learning with understanding [3]. Conceptual understanding consists of relation, comparison, assimilation, and re-organization to the new knowledge with the existing knowledge and transferring it to solve the new problem. Conceptual understanding is based on the re-organization of the existing knowledge. 
It is based on the cognitive constructivist theory proposed by some experts $[4,5,6$, 7].

Conceptual understanding is defined as a skill to determine which relevant and important idea to a problem and its accuracy in understanding the relation among microscopic attitude, macroscopic observation and symbol/ notation used to represent both $[8,9,10,11]$.

The concept in physics learning becomes an important key to understand and apply physics in daily life. The concept enables us to understand new experience by connecting to whatever we have known. Scientific concepts are media to help in the understanding application in daily life. Physics learning with concept understanding makes physics not only remembering, but also applying the concept.

Heat and temperature are one of physics topic that conceptual understanding still low. Heat and temperature are mostly taught as science topic at the elementary and middle level. Heat is the main discussion that becomes a basic on the phenomenon of energy transfer, an important phenomenon set on some subjects, such as physics, chemistry, and biology. The importance of heat and temperature material on all science subjects demands the students have the conceptual understanding of this concept [12]. Study of heat and thermodynamics becomes an important part of physics learning [13].

Conceptual understanding is inseparable with physics learning process. To know the students' conceptual understanding appropriate instruments are needed. There are many ways to know students' conceptual understanding, such as with the use of concept map, interview, and diagnostic test of Two-tier Multiple Choice/TTMC [14]. Two-tier Multiple Choice (TTMC) was firstly developed by David Treagust (1988) from Curtin University Australia [15]. This instrument is an objective test that consists of 2 levels. The first level is the main question (first-tier) and second level (second-tier) is the reason of answer choice. TTMC can be used to identify and to evaluate students' concept in a certain area; the answer choice on the first level is examining factual knowledge and the second level is examining the reason of choosing an answer on the first level [16].

TTMC has the better advantage than another question form. The advantage of TTMC compared with conventional multiple-choice is to decrease error on measuring. By using conventional multiple-choice with 5 answer choices, students have a $20 \%$ chance to answer it correctly by guessing. Meanwhile, TTMC has only $4 \%$ of the correct answer by guessing [14]. Therefore, students are demanded to explain their chosen answers. In addition, through TTMC, teachers can recognize students' understanding and misconception [17].

Based on the theories above, the researcher has conducted studies to investigate the students' conceptual understanding on heat and temperature. An analysis of students' concept understanding uses Two-tier Multiple Choice (TTMC) as an assessment instrument. The research question proposed in this study was "How is the students' concept understanding profile on heat and temperature?"

\section{RESEARCH METHODOLOGY}

This research was a descriptive research that described the profile of students' conceptual understanding of heat and temperature from the concept of temperature 
and expansion, heat, Black principle and heat transfer. Subjects of the research were 148 students of grade X from high, medium and low categorized school in Surakarta at the academic year of 2016/2017. The selection of school category was based on the score of the physics national exam of the last four years. The school category (high, medium and low) represents the rank of school based on national exam obtained from national exam score application called PAMER UN developed by education ministry of Indonesia. Data of the research was obtained from the result of students' test using assessment instrument of Two-tier Multiple Choice (TTMC). This instrument consisted of 30 questions that were based on the learning indicator on a syllabus.

TTMC instrument is effective to determine students' conceptual understanding and may be used as an alternative instrument to determine students' achievement [18]. TTMC instrument is developed to investigate the students' concept understanding because TTMC instrument consists of conceptual question with two level or two tier. The first level (first tier) is the main answer to evaluate students' conceptual, and the second level (second tier) is the reason of students' answer in first tier. The example of question in TTMC instrument can be seen in Figure 1.

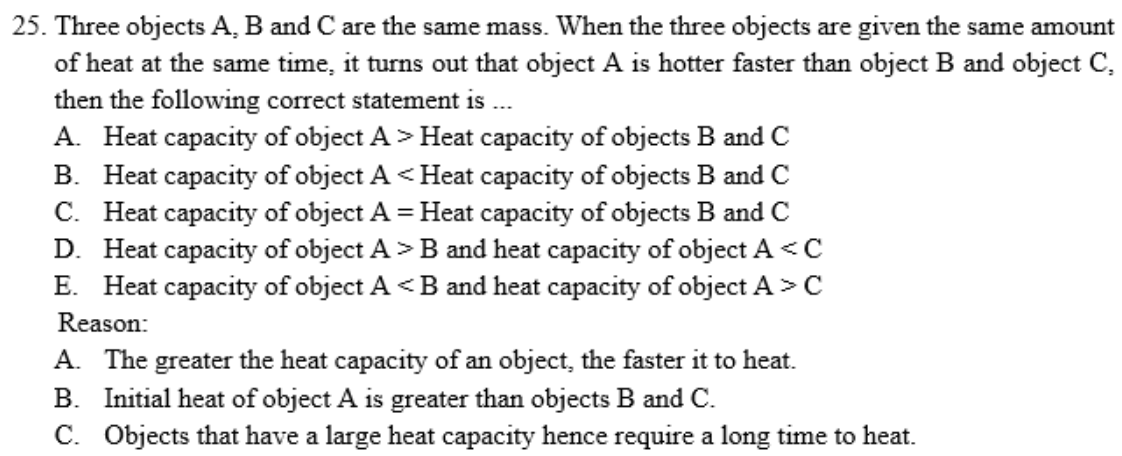

Figure 1. The example of Question in TTMC Instrument.

Based on figure 1, teachers can investigate the students' concept understanding. The form of instrument makes the students not only remember but also apply the physics concept to solve the problem in TTMC instrument.

\section{RESULTS AND DISCUSSION}

The level of students' conceptual understanding is divided into 4 categories, high, adequate, low and very low can be seen in Table I [19]. 
TABLE I. CATEGORY OF CONCEPTUAL UNDERSTANDING

\begin{tabular}{|cc|}
\hline Understanding Percentage & Understanding Category \\
$75 \%<\mathrm{P} \leq 100 \%$ & High \\
$50 \%<\mathrm{P} \leq 75 \%$ & Adequate \\
$25 \%<\mathrm{P} \leq 50 \%$ & Low \\
$0 \%<\mathrm{P} \leq 25 \%$ & Very low \\
\hline
\end{tabular}

Table I used to make the category of students' conceptual understanding based on students' answer. Students' answer had been analysed using scoring guidance or assessment rubric which then categorized its concepts. The division of the concepts was based on the syllabus used by teachers. The resulting analysis of students' answer can be seen in Table II.

TABLE II. STUDENTS' CONCEPTUAL UNDERSTANDING ON HEAT AND TEMPERATURE

\begin{tabular}{|lccccc|}
\hline \multicolumn{1}{|c}{ Concept } & $\begin{array}{c}\text { High } \\
\text { categorized } \\
\text { school }\end{array}$ & $\begin{array}{c}\text { Achievement (\%) } \\
\text { Medium } \\
\text { categorized } \\
\text { school }\end{array}$ & $\begin{array}{c}\text { Low } \\
\text { categorized } \\
\text { school }\end{array}$ & $\begin{array}{c}\text { Average } \\
(\%)\end{array}$ & $\begin{array}{c}\text { Category of } \\
\text { conceptual } \\
\text { understanding }\end{array}$ \\
$\begin{array}{l}\text { Temperature } \\
\text { and expansion }\end{array}$ & 58.19 & 46.35 & 32.92 & 45.82 & Low \\
Heat & 73.15 & 58.29 & 51.67 & 61.04 & Adequate \\
$\begin{array}{l}\text { Black } \\
\text { principle }\end{array}$ & 79.00 & 54.72 & 59.83 & 64.52 & Adequate \\
Heat transfer & 68.80 & 49.88 & 47.08 & 55.25 & Adequate \\
\hline
\end{tabular}

Table II illustrates the percentage distribution pattern which was almost the same. In each school, the concept of Black principle got the highest percentage. Based on the data at table 1, it shows that the lowest understanding percentage on the concept of temperature and expansion, meanwhile other concepts are in the adequate category. The concept of temperature and expansion has been learned by students at a junior high school.

Based the result in table II, the low percentage of students' conceptual understanding on heat and temperature materials indicates that students are still misconception in the material. This topic contains many conceptual things and becomes one of the topics that emerge misconception [13]. Heat is the most difficult physics concept in the whole of secondary science curriculum and most of students still have misconception on heat and temperature [20].

According previous researcher, misconception profile that happened states that heat is not energy, heat is same as temperature, heat can't be measured, temperature can be transferred, cold thing does not have heat, temperature is certain character owned by material or thing and water can reach temperature of $0^{\circ} \mathrm{C}$ [21].

The average percentage of students' conceptual understanding indicates that students just remembering, so physics concept not embedded in students' thinking. The achievement graphic of students' conceptual understanding of high, medium and low categorized school can be seen in Figure 2. 


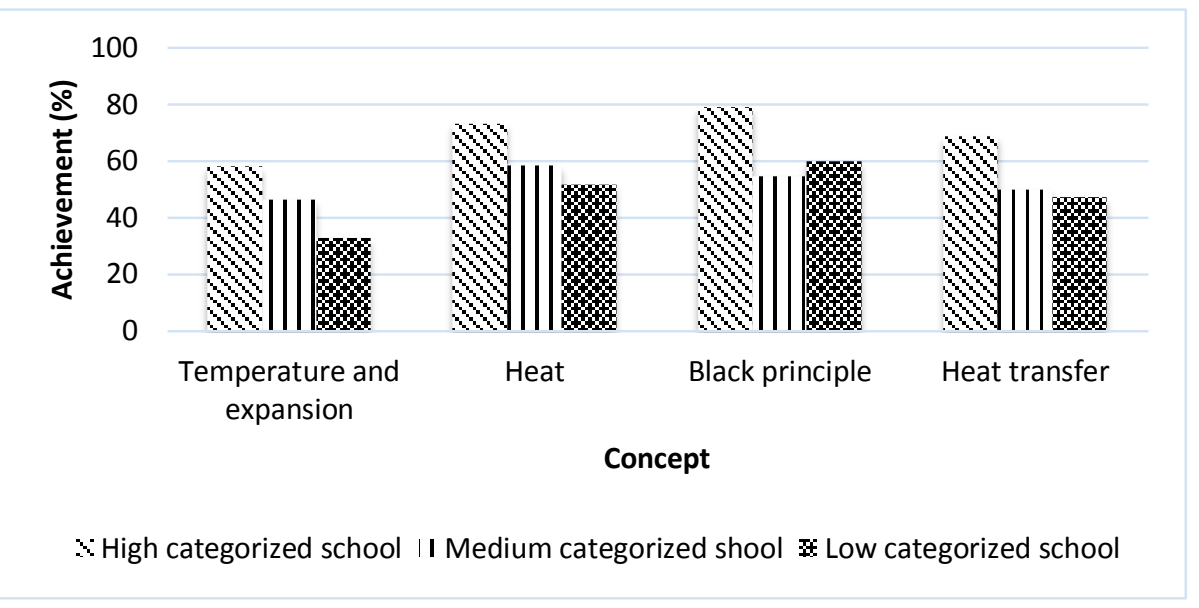

Figure 2. The achievement graphic of students' conceptual understanding at each school

Figure 1 shows the different achievement of each concept at high, medium and low categorized school. The three schools show the achievement percentage that is not much different. The highest achievement percentage is on heat concept and the lowest achievement is the concept of temperature and expansion. The lowest achievement in thermodynamic concept includes heat and temperature is also stated by another researcher, from 214 subjects of high school students indicated that $80 \%$ received 0-5 marks and 20\% received 6-9 marks. This result indicates that most of the students has low conceptual understanding and lacked the understanding of heat and thermodynamic concepts [22].

Based on the result of the students' interview, the low concept understanding on the concept of temperature and expansion was because they have been influenced by the previous concepts, whereas those concepts were not totally correct. The students' different concept can be influenced by many factors. One of those factors is that each student builds different basic concept. It is because students come to the class with different knowledge that is built from their daily life. Students' knowledge on the concept of heat and temperature is gained from daily life because it relates directly to daily life. Therefore, heat and temperature can't be observed directly [23]. Students come from various impression and concept in their daily life. Many impressions and concepts may be wrong [24].

The students' mistake on the concept of temperature and expansion was commonly found because they could not differentiate the characteristic of liquid thermometer filler. Students could not differentiate the boiling and melting point of some substance thermometer filler. Another mistake on this concept was that students were still confused in differentiating between specific heat, thermal conductivity, and long expansion coefficient. Most of the students consider that expansion was influenced by the value of specific heat and metal conductivity.

Students' difficulty in differentiating basic terms on temperature and heat was also stated by another researcher. Students still related the concept of thermal conductivity with cold-hot objects. Students were also confused in differentiating the concept of thermal conductivity and specific heat [25]. 
Temperature and heat are one of the difficult concepts to be learned [20].Those concepts are too abstract and emerge various thoughts when students learn it. For instance, heat concept considered as flowing energy is recognized as material or substance formed like air or stream [26]. Students found high difficulty to accept that different objects would have the same temperature when it was touched at the same environment in same times [27]. Nevertheless, temperature and heat is a key concept used to understand other scientific concepts [20].

The concept of temperature and heat is an important concept because it becomes a basis for other concepts. For example, a concept of temperature and heat is a concept that must be previously understood by students to be able in explaining thermodynamics law. On the material of electric series, the concept of temperature and heat takes a part in determining materials used in an electronic series. Modern physics cannot be separated from temperature formula as an important factor that always influences other factors.

Because of the importance of conceptual understanding on the material of temperature and heat, it needs to conduct a profile analysis of students' conceptual understanding. This analysis is important to decide the next teachers' action. Getting knowledge on students' misconception can help teachers to design learning approach that focuses on conceptual understanding. It belongs to a strategy based on the way to face students with idea disability and their strategy in building a way from a situation in which students' intuitive respond is appropriate with a scientific statement [28].

Profile analysis of students' conceptual understanding used instrument of TTMC. TTMC is two-level instrument that can solve the weakness of multiple choice instrument in the tendency of guessing. TTMC consists of more complicated questions than other common multiple-choice forms. The main level (first tier) seems like traditional multiple-choice form (Multiple Choice Question/MCQ), in which it concerns about knowledge aspect. The second level (two-tier) seems like the format of the questions of traditional multiple-choice. However, its aim is to increase the skill of high level and expressing reasons [29].

The developed of TTMC diagnostic test to measure students' conception. The first tier of each question related to propositional statements and parts of concept maps, and the second tier of each question contain a set of reason for answer in the first tier. The set option if second tier consist of possible misconceptions held by students [30].

The scoring on the TTMC instrument used Graded Response Model (GRM) method adapted from Yamtinah [31] and classification of concept understanding from Tekkaya [32]. The scoring guidance of TTMC instrument can be seen in Table III. 
TABLE III. SCORING ON INSTRUMENT OF TWO-TIER MULTIPLE CHOICE (TTMC)

\begin{tabular}{|c|c|c|c|}
\hline No & Assessment aspect & Score & $\begin{array}{c}\text { Classification of conceptual } \\
\text { understanding }\end{array}$ \\
\hline 1 & $\begin{array}{l}\text { Do not choose any answer and reason, } \\
\text { or wrong answer-wrong reason }\end{array}$ & 0 & Do not understand \\
\hline 2 & Wrong answer-correct reason & 1 & $\begin{array}{l}\text { Partial understanding with } \\
\text { misconception }\end{array}$ \\
\hline 3 & Correct answer-wrong reason & 2 & $\begin{array}{l}\text { Partial understanding with } \\
\text { misconception }\end{array}$ \\
\hline 4 & Correct answer-correct reason & 3 & Sound understanding \\
\hline
\end{tabular}

The assessment of students' conceptual understanding using scoring guidance is at table 3 to ease the teachers in knowing the pattern of students' answer. Besides that, through this scoring teachers are able to know students' understanding through the answer given at the first and the second level. Therefore, this instrument can help teachers to make students' profile.

Students' profile can support teachers' information media to know how far the indicators have been reached by students and its difficulty [33]. Students' profile analysis was made by using Microsoft Excel program. Profile analysis of science process skill using Microsoft Excel was developed by a research from Wulandari, et al. (2015) [33]. Students' profile analysis using Microsoft Excel program only needed a simple formula to obtain the profile of students' conceptual understanding. The answer key, students' answer, and indicators on each question were imported to Microsoft Excel program to obtain category of concept understanding on each number and its achievement percentage of concept understanding on each student. The profile display of each student can be seen in Figure 3. 


\begin{tabular}{|c|c|c|c|c|}
\hline \multicolumn{5}{|c|}{ STUDENTS' PROFILE } \\
\hline \multicolumn{5}{|c|}{ Students' Identity } \\
\hline Name & $:$ NN & & & \\
\hline Number & $: 6$ & & & \\
\hline Class & : X MIA 1 & & & \\
\hline \multirow{2}{*}{ Number } & \multirow{2}{*}{ Score } & \multicolumn{2}{|c|}{ Indicator } & \multirow{2}{*}{$\begin{array}{c}\text { Classification of conceptual } \\
\text { understanding }\end{array}$} \\
\hline & & Achieved & Have not achieved & \\
\hline 1 & 3 & $\begin{array}{l}\text { Being able to determine factors and relation among } \\
\text { variables that influence the amount of heat needed. }\end{array}$ & 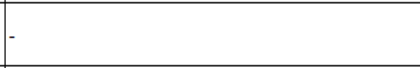 & Sound understanding \\
\hline 2 & 0 & - & $\begin{array}{l}\text { Determining factors and relation among variables that } \\
\text { influence the amount of heat needed to increase } \\
\text { temperature. }\end{array}$ & Do not understand \\
\hline 3 & 1 & $\begin{array}{l}\text { Being able to determine factors that influence the } \\
\text { temperature rise. }\end{array}$ & $\begin{array}{l}\text { Making relation graphic between temperature and } \\
\text { heating time by observing the free and bound variable. }\end{array}$ & $\begin{array}{l}\text { Partial understanding with } \\
\text { misconception }\end{array}$ \\
\hline 4 & 3 & $\begin{array}{l}\text { Being able to design an experiment and to explain } \\
\text { process in determining the relation between heat and } \\
\text { temperature change. }\end{array}$ & - & Sound understanding \\
\hline 5 & 1 & $\begin{array}{l}\text { Being able to analyze factors that influence the amount } \\
\text { of heat needed. }\end{array}$ & Counting the heat needed to increase temperature & $\begin{array}{l}\text { Partial understanding with } \\
\text { misconception }\end{array}$ \\
\hline 7 & 0 & $\begin{array}{l}\text { Being able to determine factors that influence heat } \\
\text { conductivity }\end{array}$ & $\begin{array}{l}\text { Applying the concept of thermal conductivity material } \\
\text { Analyzing the amount of heat absorbed by objects } \\
\text { because of the influence of temperature change and } \\
\text { object specific heat. }\end{array}$ & $\begin{array}{l}\text { Partial understanding with } \\
\text { misconception } \\
\text { Do not understand }\end{array}$ \\
\hline 8 & 1 & Being able to apply expansion concept. & Comparing metal diameter before and after heated. & $\begin{array}{l}\text { Partial understanding with } \\
\text { misconception }\end{array}$ \\
\hline 9 & 1 & $\begin{array}{l}\text { Being able to determine the amount of boiling point on } \\
\text { each material of thermometer filler. }\end{array}$ & $\begin{array}{l}\text { Choosing a thermometer that is appropriate with the } \\
\text { characteristic of thermometer filler. }\end{array}$ & $\begin{array}{l}\text { Partial understanding with } \\
\text { misconception }\end{array}$ \\
\hline 10 & 2 & $\begin{array}{l}\text { Being able to formulate hypothesis according to its } \\
\text { experiment purpose. }\end{array}$ & Determining factors that influence expansion & $\begin{array}{l}\text { Partial understanding with } \\
\text { misconception }\end{array}$ \\
\hline 11 & 1 & $\begin{array}{l}\text { Being able to determine the steps that must be } \\
\text { conducted to reach the aim of the experiment. }\end{array}$ & Designing experiment procedure of liquid expansion & $\begin{array}{l}\text { Partial understanding with } \\
\text { misconception }\end{array}$ \\
\hline 12 & 3 & $\begin{array}{l}\text { Being able to determine the rate of the highest heat } \\
\text { transfer based on the data and applying the concept of } \\
\text { thermal conductivity material. }\end{array}$ & 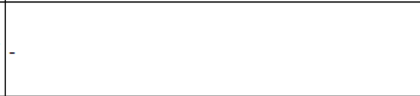 & Sound understanding \\
\hline 13 & 3 & $\begin{array}{l}\text { Being able to determine the factors that fasten the } \\
\text { expansion and applying expansion concept. }\end{array}$ & - & Sound understanding \\
\hline 14 & 3 & $\begin{array}{l}\text { Being able to determine process of form change on the } \\
\text { process of water heating and applying the concept of } \\
\text { form change that happens at the process of water } \\
\text { heating. }\end{array}$ & 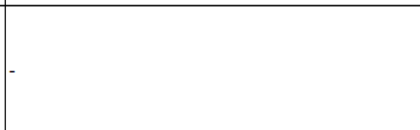 & Sound understanding \\
\hline
\end{tabular}

Figure 3. The example of display profile of students' conceptual understanding using Microsoft Excel program

Figure 3 shows the profile of students' conceptual understanding. In that profile, teachers can see the score on each number, learning indicators that have been achieved and not, and the category of students' conceptual understanding on each number. Besides that, teachers can also see the achievement percentage of students' conceptual understanding of each concept. On the material of temperature and heat, there are 4 main concepts, such as temperature and expansion, heat, Black principle and heat transfer.

Besides to know the achievement percentage on each concept, teachers can also see the total category of students' conceptual understanding. The determination of the category of students' conceptual understanding using guidance is at table 1 . The analysis result of the conceptual understanding category of 148 students can be seen in Table IV. 
TABLE IV. CATEGORY OF STUDENTS' CONCEPTUAL UNDERSTANDING

\begin{tabular}{|cc|}
\hline Category of conceptual understanding & Students' percentage (\%) \\
High & 18.92 \\
Adequate & 53.38 \\
Low & 27.03 \\
Very low & 0.68 \\
\hline
\end{tabular}

Based on Table IV, a category of students' conceptual understanding is totally dominated on an adequate category. This case shows that it still needs a serious attempt from the teachers and the students in order that physics concept (mainly on the material of temperature and heat) can be absorbed maximum by students. Category graphic of students' conceptual understanding can be seen in Figure 4.

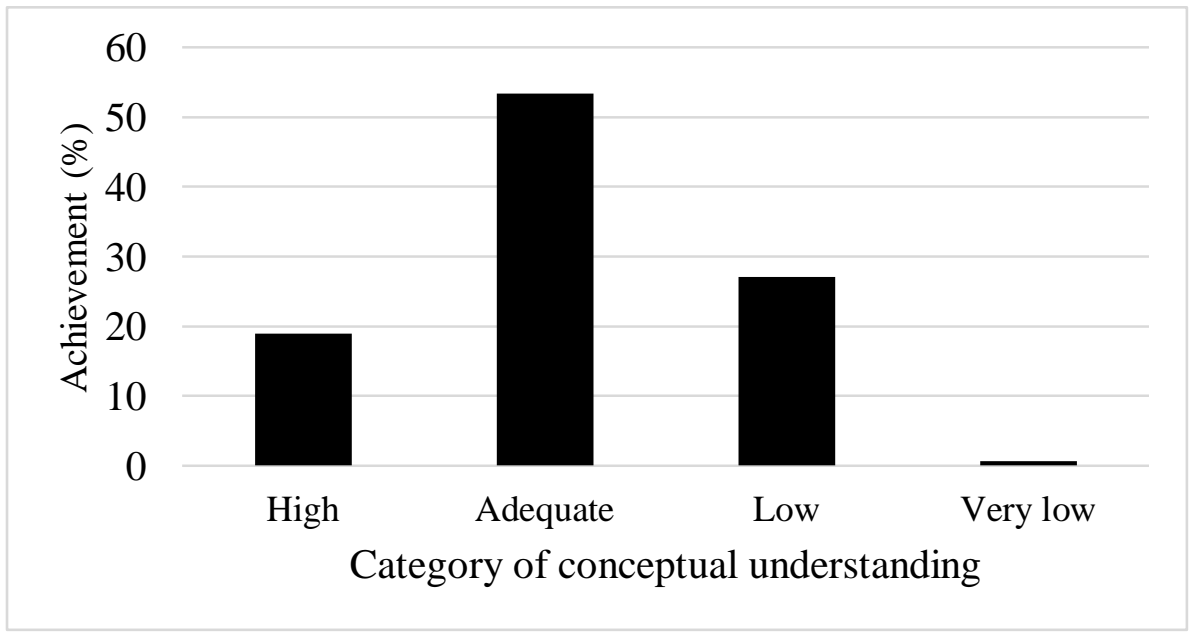

Figure 4. Category graphic of students' conceptual understanding of the material of temperature and heat

At figure 4, it is clearly shown the different percentage of each category of students' conceptual understanding. The low category of students' conceptual understanding is because the students only memorize the science terms. Many students spend their time and attempt to focus on the learning result that is less important such as memorizing science vocabularies or factual information, however, they do not attempt to reach conceptual understanding [34, 35].

Besides that, students only rely on the explanation of science concept that is not adequate with distorting scientific knowledge to be appropriate with their own knowledge, without thinking to answer questions or to copy the answer from texts or their classmates $[34,35]$.

Several concept understanding consists of more than relation memories; conceptual understanding needs the skill to apply the previous learning in the previous unexpected experience [36]. Therefore, conceptual understanding can be defined as an Ausubelian meaningful learning rather than memorizing learning. 


\section{CONCLUSIONS}

Based on the data and analysis, most of students in high, medium and low categorized school have low concept understanding in temperature and expansion concept, in other concept (heat, Black principle and heat transfer) have adequate concept understanding. From this research, teachers know the students' concept understanding and teachers can choose the suitable learning method in physics learning activities. In other hand, teachers can develop and apply two-tier multiple choice as alternative instrument, not only traditional multiple choice and essay test to investigate students' concept understanding.

\section{REFERENCES}

[1] Gardner, H. 1999. The discipline mind: What all students should understand. New York: Simon \& Schuster Inc.

[2] McDermott L C \& Reddish E F. 1999. Resource Letter on Physics Education Research. The American Journal of Physics, 67(9): 755-767.

[3] Driver, R., Asoko, H., Leach, J., Scott, P., \& Mortimer, E. 1994. Constructing scientific knowledge in the classroom. Educational researcher, 23(7): 5-12. http://dx.doi.org/10.3102/0013189X023007005

[4] Duit, R. 1999. Conceptual change approaches in science education. New perspectives on conceptual change, 263-282.

[5] Piaget, J. 1951. The child's conception of the world (Vol. 213): Rowman \& Littlefield.

[6] Posner, G. J., Strike, K. A., Hewson, P. W., \& Gertzog, W. A. 1982. Accommodation of a scientific conception: Toward a theory of conceptual change. Science Education, 66(2): 211-227. http://dx.doi.org/10.1002/sce.3730660207

[7] Tobin, K., Tippins, D., \& Gallard, A. 1994. Research on instructional strategies for teaching science.[In DL Gabel (Ed.), Handbook of research on science teaching and learning (pp. 45-93). New York: Macmillan

[8] Nakhleh, M.B. 1993. Are Our Students Conceptual Thinker or Algorithmic Problem Solver? Journal of Chemical Education, 70(3): 52-55.

[9] Nurrenbern, S. C. \& Pickering, M. 1987. Concept learning versus problem solving: Is there a difference? Journal of Chemical Education, 64(6): 508 - 510.

[10] Pickering, M. 1990. Further studies on concept learning versus problem solving: Is there a difference? Journal of Chemical Education, 67: 254-255.

[11] Johnstone, A.H. 2006. Chemical education research in Glasgow in perspective. Chemistry Education Research and Practice, 7(2): 49-63.

[12] Wiser, M. 1986. The differentiation of heat and temperature: an evaluation of the effect of microcomputer teaching on students' misconceptions. Technical report of educational research and improvement.

[13] Pathare, S. R and Pradhan, H. C. 2010. Students' misconceptions about heat transfer mechanisms and elementary kinetic theory. Physics education 45 (6): $629-634$.

[14] Tuysuz, C. 2009. Development of Two-Tier Diagnostic Instrument and Assess Students' Understanding in Chemistry. Scientific Research and Essay, 4(6): 626--631.

[15] Treagust, D. F. 1988. The development and use of diagnostic instruments to evaluate students' alternative conceptions in science. International Journal of Science Education, 10(2): 159-169.

[16] Treagust, D. F. 1995. Diagnostic assessment of students' science knowledge. In S. M. Glynn \& R. Duit. (Eds.), Learning Science in the Schools: Research Reforming Practice (pp. 327-346). Mahwah, New Jersey: Lawrence Erlbaum Associates.

[17] Kutluay, Y. 2005. Diagnosis of Eleventh Grade Students' Misconceptions about Geometric Optic by a Three-Tier Test. Thesis not published.

[18] Winarti, Cari, Suparmi, Sunarno, W., Istiyono, E. 2017. Development of two tier test to assess conceptual understanding in heat and temperature. IOP Conf. Series: Journal of Physics: Conf. Series 795 (2017) 012052. 
[19] Sugiyono. 2010. Metode penelitian pendidikan (Pendekatan kualitatif, kuantitatif dan R\&D). Bandung: Alfabeta

[20] Sözbilir, M. 2003. A Review of Selected Literature on Students' Misconceptions of Heat and Temperature. Journal of Education, 20(1): 25-41.

[21] Yeo \& Zadnik. 2001. Introductory Thermal Concept Evaluation: Assesing Students' Understanding. The Physics Teacher: American Association of Physics Teachers, 39(8): 496-504.

[22] Kruatong, T., Sung-ong, S., Singh, P., and Jones, A. 2006. Thai High School Students' Understanding of Heat and Thermodynamics. Social Sciences 27: $321-330$.

[23] Arnold, M. \& R. Millar. 1994. Children's and Lay Adults' Views About Thermal Equilibrium 'Work' and 'Heat': on a Road Towards Thermodynamics. International Journal of Science Education, 16(4): 131-144.

[24] Kartal, T., Ozturk, N., \& Yalvac, H.G. 2011. Misconceptions of Science Teacher Candidates about Heat and Temperature". Procedia Social and Behavioral Sciences, 15: 2758-2763.

[25] Quan, G. 2011. Improvements of Student Understanding of Heat and Temperature. Journal of University of Washington Research Experience for Undergraduates 2011 and the Physics Education Group.

[26] Baser, M. 2006. Effect of Conceptual Change Oriented Instruction on Students' Understanding of Heat and Temperature Concept. Journal of Maltese Education Research, (On-line), 4(1): 64-79.

[27] Thomas, M. F. Malaquis et al. 1995. An Attempt to Overcome Alternative Conception Related to Heat and Temperature. Physics Education. 30: 19-26

[28] Saricayir, H., Ay S., Comek A., Cansiz G., Uce1, M. 2016. Determining Students' Conceptual Understanding Level of Thermodynamics. Journal of Education and Training Studies, 4(6): 69-79

[29] Adodo, S. O. 2013. Effects of Two-Tier Multiple Choice Diagnostic Assessment items on Students' Learning Outcome in Basic Science Technology. Ondo State: Academic Journal of Interdisciplinary Studies, 2(2): 201-210.

[30] Treagust, D. F. (1985). Diagnostic tests to evaluate students' misconceptions in science. Paper presented at the annual meeting of the National Association for Research in Science Teaching, French Lick Springs, Indiana.

[31] Yamtinah, S., Haryono, Saputro, S., Mulyani, B., Suryadi, BU. 2016. Item discrimination of two-tier test on hydrolysis of salt. Proceeding International Conference on Educational Research and Evaluating (ICERE),(pp. 360-365).

[32] Tekkaya, et al 1999. A Cross-Age Study of High School Student's Understanding of Diffusion and Osmosis. Hacettepe Universitesi Egitim FakUltesi Dersigi, 15, 84-93.

[33] Wulandari, R.R.A., Yamtinah, S. Saputro, S. 2015. Instrumen Two Tier Test Aspek Pengetahuan Untuk Mengukur Ketrampilan Proses Sains (KPS) pada Pembelajaran Kimia Untuk Siswa SMA/MA Kelas XI. Jurnal Pendidikan Kimia (JPK). 4(4): 147-155.

[34] Anderson, C.W., \& Roth, K. J. 1989. Teaching for Meaningful Understanding and Self-Regulated Learning of Science. In J. Brophy (Ed.), Teaching for Meaningful Understanding and Self-Regulated Learning (p. 265-309). Greenwich, CT: JAI Press.

[35] Blumenfeld, P. C., \& Meece, J. L. 1988. "Task Factors, Teacher Behavior, and Students' Involvement and Use of Learning Strategies in Science". The Elementary School Journal, 88 (3): 235250.

[36] Smith, P. L., \& Ragan, T. J. 1999. Instructional design: Wiley New York, NY. 